\title{
EFEK LATIHAN FISIK TERHADAP VO2 MAX PADA MAHASISWA
}

\section{The Effectivity Of Physical Exercise On Vo2 Max In Students}

\author{
Aco Tang, Muh Thahir \\ Jurusan Fisioterapi Polteknik Kesehatan Makassar \\ Email Korespondensi: acotang45@gmail.com
}

\begin{abstract}
Vo2 max is the maximum amount of oxygen consumed per minute when a person has reached maximum effort. This study aims to determine the effect of physical exercise on vo2 max level 1 students of the physiotherapy department health polytechnic of makassar. This research is a field experimental study involving treatment variables, namely physical exercise, while the response variable is vo2 max. The research design was a quasy experiment with a pretestpost test two group design. The study population was level 1 students of the diii of physiotherapy physiotherapy department health polytechnic of makassar as many as 50 people, while the sample of level 1 students of the diii of physiotherapy physiotherapy department health polytechnic of makassar was 40 people, with random sampling technique divided into 2 (two) groups, one treatment group of 20 people and one control group of 20 people. This study bleep test to measure vo2 max before and after the administration of intervention twice a week for 8 weeks. It can be concluded that there is an effect of providing physical training to the change in vo2 max of the first level students of health polytechnic of makassar. This research is expected to be a material consideration for health workers in promoting and providing health services in the form of physical training to increase vo2 max.
\end{abstract}

Keywords: physical exercise, vo2 max, students

\section{ABSTRAK}

Vo2 max merupakan jumlah oksigen maksimal yang dikonsumsi permenit ketika seseorang telah mencapai usaha maksimal. Penelitian ini bertujuan untuk mengetahui pengaruh latihan fisik terhadap vo2 max mahasiswa tingkat 1 jurusan fisioterapi poltekkes makassar. Penelitian ini termasuk penelitian eksperimen lapangan yang melibatkan variabel perlakuan yaitu latihan fisik, sedangkan variabel respons adalah vo2 max. Desain penelitian adalah quasy experiment dengan desain pretest-post test two group design. Populasi penelitian adalah mahasiswa tingkat 1 program studi d.iii fisioterapi poltekkes kemenkes makassar sebanyak 50 orang, sedangkan sampel mahasiswa tingkat 1 program studi d.iii fisioterapi poltekkes kemenkes makassar sebanyak 40 orang, dengan teknik sampling secara random sampling dibagi menjadi 2 (dua) kelompok, satu kelompok perlakuan yang berjumlah 20 orang dan satu kelompok kontrol yang berjumlah 20 orang. Penelitian ini bleep test untuk mengukur vo2 max sebelum dan sesudah pemberian intervensi 2 kali seminggu selama 8 minggu. Dapat disimpulkan bahwa terdapat pengaruh pemberian latihan fisik terhadap perubahan vo2 max mahasiswa tingkat i poltekkes kemenkes makassar. Penelitian ini diharapkan menjadi bahan pertimbangan bagi tenaga kesehatan dalam upaya promotif maupun pengadaan pelayanan kesehatan berupa latihan fisik untuk meningkatkan vo2 max.

Kata kunci : latihan fisik, vo2 max , mahasiswa

\section{PENDAHULUAN}

Pelayanan

promotif, preventif, kuratif dan rehabilitatif yang meliputi kondisi-kondisi seperti musculoskeletal, neuromuscular, geriatri dan pediatrik. Pelayanan fisioterapi meliputi pelayanan dari berbagai tingkatan usia perkembangan, dari bayi sampai usia lansia. Dalam menjalankan peran dan fungsinya seorang fisioterapis dapat mandiri, ketergantungan dan saling ketergantungan. Pelayanan fisioterapi yang mandiri umumya untuk jenis pelayanan yang bersifat promotif dan preventif misalnya pengukuran tentang kebugaran tubuh (Menkes, 2015).

Kebugaran yang berhubungan dengan kesehatan meliputi komposisi tubuh, daya tahan kardiorespirasi, vo2 max, kekuatan otot, daya tahan otot, flexibilitas (Medicine, 2018). Pengambilan oksigen maksimal (VO2max) adalah indikator utama kebugaran kardiorespirasi (Jamnick et al., 2016).

VO2 max adalah suatu ukuran kapasitas tubuh dalam menggunakan oksigen. VO2 max merupakan jumlah oksigen maksimal yang dikonsumsi permenit ketika seseorang telah mencapai usaha maksimal. Sebagian besar ilmuan olahraga mengatakan bahwa VO2 max merupakan aerobik power dimana sebagai pemeriksaan laboratorium yang paling objektif untuk mengukur kapasitas daya tahan jantung paru. Meskipun beberapa ilmuan olahraga telah menjelaskan bahwa VO2 max sebagai prediktor yang baik untuk 
kesuksesan pada pertandingan atau perlombaan yang membutuhkan endurance, pemenang lari maraton yang dapat diprediksi ukuran VO2 max secara laboratorium. Tes performance untuk lari jarak jauh adalah salah satunya tes VO2 Maks dimana masih memberikan performance yang lebih baik dari pada VO2 max yang tinggi (Kisner et al., 2017).

VO2 max juga dapat diartikan sebagai kemampuan maksimal seseorang untuk mengkonsumsi oksigen selama aktivitas fisik pada ketinggian yang setara dengan permukaan laut. VO2 max merefleksikan.

keadaan paru, kardiovaskuler, dan hematologik dalam pengantaran oksigen, serta mekanisme oksidatif dari otot yang melakukan aktivitas. Selama menit-menit pertama latihan, konsumsi oksigen meningkat hingga akhirnya tercapai keadaan steady state di mana konsumsi oksigen sesuai dengan kebutuhan latihan. Bersamaan dengan keadaan steady state ini terjadi pula adaptasi ventilasi paru, denyut jantung, dan cardiac output.

Seorang mahasiswa memerlukan energi yang tinggi dalam melaksanakan kegiatannya, seperti berangkat kuliah di pagi hari, mengikuti kuliah sampai sore bahkan belajar mandiri dan mengerjakan tugas pada waktu malam, hal ini memerlukan kebugaran fisik yang baik.

Penelitian telah menjelaskan bahwa peningkatan VO2 max setelah program training hanya terjadi selama $8-12$ minggu kemudian nilai VO2Maks tersebut akan datar (tidak meningkat) meskipun masih melakukan program training intensitas tinggi. Walaupun VO2Maks tidak dapat meningkat secara berkesinambungan, beberapa orang yang terlibat dalam program training dapat secara terus menerus memperbaiki performance enduransnya dimana dapat berkembang kemampuannya yang lebih besar untuk melakukan persentase VO2max yang tinggi. Sebagai contoh, sebagian besar pelari dapat menyelesaikan jarak lari $42 \mathrm{~km}$ pada kecepatan rata-rata dengan menggunakan sekitar 75-80\% VO2Maksnya (Kisner et al., 2017).

Penelitian ini merupakan lanjutan dari penelitian sebelumnya dengan judul gambaran VO2 max Mahasiswa Tingkat I Program Studi D.III Jurusan Fisioterapi Poltekkes Kemenkes Makassar, dengan hasil $85 \%$ mahasiswa memiliki kebugaran sangat buruk dan $15 \%$ buruk. VO2 max dapat ditingkatkan dengan latihan fisik. Hal ini menarik perhatian penulis untuk meneliti Pengaruh latihan fisik terhadap VO2 max Mahasiswa Tingkat I Program Studi D.III Jurusan Fisioterapi Poltekkes Kemenkes Makassar.

\section{METODE}

\section{Desain dan Waktu Penelitian}

Penelitian dilaksanakan pada 10 April - 15 Juni 2019 di Kampus Poltekkes Kemenkes Makassar.

\section{Populasi dan Sampel}

Populasi adalah semua mahasiswa Tk. I Program Studi D.III Fisioterapi Poltekkes Kemenkes Makassar sebanyak 50 orang, Sampel yang diambil sebanyak 40 orang sesuai kriteria inklusi dan kriteria ekslusi.

\section{Instrumen Pengumpulan Data}

Alat atau instrumen yang digunakan untuk mempermudah proses pengumpulan data dalam penelitian ini adalah pengukuran vo2max dengan bleep test.

\section{Analisa Data}

Data yang diperoleh dianalisis dengan menggunakan uji normalitas yang dilanjutkan dengan uji pengaruh. Pengolahan dan analisis data dengan menggunakan SPSS, kemudian disajikan dalam bentuk tabel dan narasi.

\section{HASIL}

Tabel 1. menunjukkan distribusi umur mahasiswa tingkat 1 di Poltekkes Kemenkes pada kelompok perlakuan yang terbanyak adalah umur 19 tahun sebanyak 13 orang $(65,0 \%)$ sedangkan umur 18 tahun dan 20 tahun masing-masing 6 orang $(30,0 \%)$ dan 1 orang $(5,0 \%)$. Pada kelompok kontrol yang terbanyak adalah umur 19 tahun sebanyak 11 orang $(55,0 \%)$ sedangkan umur 18 tahun dan 20 tahun masing-masing 8 orang $(40,0 \%)$ dan 1 orang $(5,0 \%)$.

Tabel 2. menunjukkan distribusi Jenis kelamin mahasiswa tingkat 1 di Poltekkes Kemenkes untuk kelompok perlakuan yang terbanyak adalah perempuan sebanyak 20 orang $(100,0 \%)$, sedangkan pada kelompok kontrol, perempuan sebanyak 17 orang $(85 \%)$ dan laki-laki sebanyak 3 orang $(15 \%)$. 
Tabel 3. menunjukkan bahwa tingkat kebugaran mahasiswa tingkat 1 di Poltekkes Kemenkes untuk kelompok perlakuan pada pre test adalah kurang sekali sebanyak 20 orang $(100,0 \%)$ sedangkan pada post test kurang sebanyak 6 orang $(30,0 \%)$ dan kurang sekali sebanyak $14(70 \%)$.

Tabel 4 menunjukkan bahwa tingkat kebugaran mahasiswa tingkat 1 di Poltekkes Kemenkes adalah kurang sekali sebanyak 16 orang $(80,0 \%)$ sedangkan kurang sebanyak 4 orang $(20,0 \%)$ baik pre test maupun post test.

Tabel 5 menunjukkan rata-rata VO2 max kelompok perlakuan adalah pre test $21,70 \pm 1,25$ naik menjadi 22,28 pada post test. Uji statistik wilcoxon menunjukkan ada pengaruh yang bermakna dengan nilai $p$ 0,006 .

Tabel 6 mununjukkan rata-rata VO2max pre test adalah $22,62 \pm 2,318$ naik menjadi $22,56 \pm 2,241$ pada post test. Uji statistik wilcoxon menunjukkan ada pengaruh yang bermakna dengan nilai $p$ 0,028 pada tingkat kepercayaan $95 \%$.

Tabel 7 mununjukkan rata-rata peningkatan VO2max pada kelompok perlakuan sebesar 2,075 $\pm 4,420$ sedangkan pada kelompok kontrol terjadi peningkatan sebesar 0.07士 0,625. Uji statistik Man whitney menunjukkan ada beda pengaruh yang bermakna dengan nilai $p 0,028$. Hal ini menunjukkan bahwa kelompok perlakuan memiliki peningkatan yang lebih besar daripada kelompok kontrol

\section{PEMBAHASAN}

Latihan fisik memberikan pengaruh yang bermakna terhadap Vo2 max mahasiswa melalui uji wilcoxon dengan nilai $\rho 0,000$. Pada penelitian ini menunjukkan bahwa terjadi peningkatan VO2 max yang bermakna.

Perubahan yang paling nampak terlihat setelah melakukan latihan fisik adalah peningkatan kemampuan melakukan latihan sub maksimal dalam waktu yang lama dan peningkatan kapasitas aerobik maksimal seseorang (VO2max). Derajat perbaikan pada endurance sub maksimal dan VO2max bervariasi setelah pemberian program training. Beberapa orang dapat mengalami perbaikan VO2max sebesar $20-30 \%$ sebagai konsekuensi dari program training tetapi beberapa orang juga dapat mengalami perubahan VO2max yang kecil (kurang dari 5\%). Secara umum peningkatan rata-rata VO2 Max dari program training bervariasi antara 15 $20 \%$.

Dari penelitian dijelaskan bahwa sebagian besar perbaikan terjadi selama 4 minggu pertama dari program training. Astorinoet.al (2017) telah mengobservasi laki-laki yang aktif melakukan program training dimana menunjukkan $15,6 \%$ terjadi peningkatan VO2max secara normal pada laki-laki yang aktif melakukan aktivitas bersepeda selama 2 jam perhari dengan lima sampai enam kali seminggu selama 8 minggu.

Penelitian ini sejalan dengan penelitian yang dilakukan oleh Wen et.al (2019) yang menyatakan latihan fisik (high intensity interval training) dapat meningkatkan vo2 max pada orang dewasa. Penelitian ini juga sejalan dengan penelitian yang dilakukan oleh Arun et.al (2019) yang meneliti pada orang diabetes dengan hasil aerobik training secara signifikan meningkatkan vo2 max pada lakilaki obesitas.

Kenaikan cardiac output pada kontraksi isotonik ini dapat mencapai nilai 35 liter/menit, yaitu jumlah yang sebanding dengan pemakaian $\mathrm{O} 2$ yang meningkat. Kenaikan cardiac output dalam hal ini terjadi oleh kenaikan stroke volume maupun denyut jantung. Penambahan denyut jantung disebabkan oleh rangsangan simpatik adrenergik, oleh berkurangnya tonus syaraf vagus, dan refleks Bainbridge.

Latihan daya tahan menghasilkan penurunan denyut nadi selama istirahat dan peningkatan stroke volume istirahat. Penurunan denyut nadi istirahat merupakan hasil dari lebih banyaknya inhibisi SA Node oleh nervus vagus, penurunan denyut nadi dipercaya berhubungan dengan peningkatan volume darah, sebagai tambahan, penelitian telah menunjukkan volume darah meningkat sekitar $500 \mathrm{ml}$ selama 8 hari training. Adaptasi ini memungkinkan atlit terlatih menghasilkan peningkatan cardiac output lebih besar dan mencapai cardiac output selama latihan (Hall, 2016).

Perubahan yang terjadi adalah denyut nadi istirahat pada atlit yang terlatih akan mengalami penurunan karena terjadi penurunan impuls simpatetik yang disertai dengan penurunan level Norefinefrin dan efinefrin serta terjadi penurunan denyut 
nadi arteri yang bersifat sekunder terhadap perubahan biokimia dalam otot dan level asitilkolin, norefinefrin dan efinefrin di dalam atrium, terjadi suatu peningkatan tonus parasimpatetik yang bersifat sekunder terhadap penurunan tonus simpatetik. Selain hal tersebut diatas perubahan lain yang terjadi adalah peningkatan volume darah dan hemoglobin yang memfasilitasi kapasistas pengiriman oksigen dalam sistem kardiovaskuler.

Cardiac output dipengaruhi oleh pengalian antara kecepatan denyut jantung dengan stroke volume. Banyak pula faktorfaktor yang mempengaruhi baik stroke volume maupun denyut jantung. Sedangkan tahanan darah perifer total terutama ditentukan oleh rangsangan susunan saraf autonom, hormon-hormon yang beredar dan penumpukan lokal dari berbagai zat kimia.

Aliran darah ke otot skelet yang sedang istrahat jumlahnya hanya 2-4 $\mathrm{ml} / 100 \mathrm{gr} / \mathrm{menit}$. Ketika berkontraksi malahan jumlah ini lebih menurun sampai berhenti oleh karena penekanan yang dialami pembuluh darah dalam otot akibat kontraksi. Pada kontraksi lebih dari 10\% dari tegangan maksimal, sudah mulai penekanan terhadap pembuluh darah, sedangkan jika tegangan kontraksi otot mencapai $70 \%$ nilai maksimal, aliran darah sama sekali terhenti. Tetapi diantara masa kontraksi, jumlah aliran darah ke dalam otot meningkat sampai 30 kali lebih banyak.

\section{KESIMPULAN DAN SARAN}

Terdapat pengaruh pemberian latihan fisik terhadap perubahan VO2 max mahasiswa tingkat I Poltekkes kemenkes Makassar. Perubahan VO2 max secara signifikan dapat dilihat pada data yang didapatkan dari awal sebelum dilakukan latihan fisik hingga ada data pengukuran yang dilakukan pada post test. Kelompok perlakuan mengalami peningkatan VO2 max lebih banyak daripada kelompok kontrol.

Bagi tenaga kesehatan dalam upaya promotif maupun pengadaan pelayanan kesehatan berupa latihan fisik untuk kalangan mahasiswa agar VO2 max menjadi lebih optimal dan masyarakat mengetahui pentingnya latihan fisik terhadap VO2 max.

\section{DAFTAR PUSTAKA}

Arun, S., Muthueleckuvan, R., \& Muthuraj, M. (2019). Effect of aerobic training on VO2 max of diabetic men.

Astorino, T. A., Edmunds, R. M., Clark, A., King, L., Gallant, R. A., Namm, S., Fischer, A., \& Wood, K. M. (2017). High-intensity interval training increases cardiac output and VO2max. Med Sci Sports Exerc, 49(2), 265-273.

Hall, J. E. (2016). Guyton and Hall Textbook of Medical Physiology, Jordanian Edition E-Book. Elsevier.

Jamnick, N. A., By, S., Pettitt, C. D., \& Pettitt, R. W. (2016). Comparison of the YMCA and a custom submaximal exercise test for determining VO2max. Med Sci Sports Exerc, 48(2), 254-259.

Kisner, C., Colby, L. A., \& Borstad, J. (2017). Therapeutic exercise: foundations and techniques. $\mathrm{Fa}$ Davis.

Medicine, A. C. of S. (2018). ACSMs Guidelines for exercise testing and prescription, Thenth edition. American College of Sports Medicine, p150.

Menkes. (2015). Peraturan Menteri Kesehatan Republik Indonesia Nomor 65 Tahun 2015 Tentang Standar Pelayanan Fisioterapi. In PMK 65.

Wen, D., Utesch, T., Wu, J., Robertson, S., Liu, J., Hu, G., \& Chen, H. (2019). Effects of different protocols of high intensity interval training for VO2max improvements in adults: A metaanalysis of randomised controlled trials. Journal of Science and Medicine in Sport, 22(8), 941-947. 
Tabel 1. Distribusi Umur Mahasiswa tingkat 1 di Poltekkes Kemenkes Makassar

\begin{tabular}{ccccc}
\hline \multirow{2}{*}{ Umur } & \multicolumn{2}{c}{ Kelompok Perlakuan } & \multicolumn{2}{c}{ Kelompok Kontrol } \\
\cline { 2 - 5 } & $\mathbf{n}$ & $\%$ & $\mathbf{n}$ & $\%$ \\
\hline 18 tahun & 6 & 30,0 & 8 & 40,0 \\
19 tahun & 13 & 65,0 & 11 & 55,0 \\
20 tahun & 1 & 5,0 & 1 & 5,0 \\
\hline Jumlah & $\mathbf{2 0}$ & $\mathbf{1 0 0 , 0}$ & $\mathbf{2 0}$ & $\mathbf{1 0 0 , 0}$ \\
\hline
\end{tabular}

Sumber : Data Primer, 2019

Tabel 2. Distribusi Jenis Kelamin Mahasiswa tingkat 1 di Poltekkes Kemenkes Makassar

\begin{tabular}{ccccc}
\hline \multirow{2}{*}{ Jenis Kelamin } & \multicolumn{2}{c}{ Kelompok Perlakuan } & \multicolumn{2}{c}{ Kelompok Kontrol } \\
\cline { 2 - 5 } & $\mathbf{n}$ & $\%$ & $\mathbf{n}$ & $\%$ \\
\hline Laki-laki & 0 & 0,0 & 3 & 15,0 \\
Perempuan & 20 & 100,0 & 17 & 85,0 \\
\hline Jumlah & $\mathbf{2 0}$ & $\mathbf{1 0 0 , 0}$ & $\mathbf{2 0}$ & $\mathbf{1 0 0 , 0}$ \\
\hline
\end{tabular}

Sumber : Data Primer, 2019

Tabel 3. Distribusi tingkat VO2 maks mahasiswa tingkat 1 Poltekkes Kemenkes Makassar kelompok perlakuan

\begin{tabular}{ccccc}
\hline \multirow{2}{*}{ Tingkat VO2 maks } & \multicolumn{2}{c}{ Pre test } & \multicolumn{2}{c}{ Post test } \\
\cline { 2 - 5 } & $\mathbf{n}$ & $\%$ & $\mathbf{n}$ & $\%$ \\
\hline Kurang & - & 0,0 & 6 & 30 \\
Kurang sekali & 20 & 100,0 & 14 & 70 \\
\hline Jumlah & $\mathbf{2 0}$ & $\mathbf{1 0 0 , 0}$ & $\mathbf{2 0}$ & $\mathbf{1 0 0 , 0}$ \\
\hline
\end{tabular}

Sumber: Data Primer, 2019

Tabel 4. Distribusi tingkat VO2 maks mahasiswa tingkat 1 Poltekkes Kemenkes Makassar kelompok kontrol

\begin{tabular}{ccccc}
\hline \multirow{2}{*}{ Tingkat VO2 maks } & \multicolumn{2}{c}{ Pre test } & \multicolumn{2}{c}{ Post test } \\
\cline { 2 - 5 } & $\mathbf{n}$ & $\%$ & $\mathbf{n}$ & $\%$ \\
\hline Kurang & 4 & 20,0 & 4 & 20,0 \\
Kurang sekali & 16 & 80,0 & 16 & 80,0 \\
\hline Jumlah & $\mathbf{2 0}$ & $\mathbf{1 0 0 , 0}$ & $\mathbf{2 0}$ & $\mathbf{1 0 0 , 0}$ \\
\hline
\end{tabular}

Sumber: Data Primer, 2019

Tabel 5. Deskripsi Nilai Rerata, Standar Deviasi (SD) dan nilai p VO2 maks pada pre test dan post test pada kelompok perlakuan

\begin{tabular}{llcc}
\hline VO2max & Mean & SD & $p$ \\
\hline Pre Test & 21,70 & 1,252 & $0,006^{*}$ \\
Post Test & 22,28 & 1,740 & \\
\hline
\end{tabular}

*Uji Wilcoxon 
Tabel 6. Deskripsi Nilai Rerata, Standar Deviasi (SD) dan nilai p VO2 maks pada pre test dan post test pada kelompok kontrol

\begin{tabular}{llll}
\hline \multicolumn{1}{c}{ VO2max } & Mean & SD & $\mathrm{p}$ \\
\hline Pre Test & 22,62 & 2,318 & $0,607^{*}$ \\
Post Test & 22,56 & 2,241 & \\
\hline
\end{tabular}

${ }^{*}$ Uji Wilcoxon

Tabel 7. Pengaruh Latihan terhadap Perubahan VO2 Max Mahasiswa Tingkat 1 di Poltekkes Kemenkes Makassar

\begin{tabular}{lcc}
\hline VO2 max & Selisih & $p$ \\
\hline Kelompok perlakuan & $2,075 \pm 4,420$ & $0.028^{\star *}$ \\
Kelompok kontrol & $0.07 \pm-0,625$ & \\
\hline
\end{tabular}

${ }^{\star}$ Uji Man whitney 